\title{
Effect of interleukin 1 receptor antagonist on the blood-aqueous barrier after intraocular lens implantation
}

\author{
Okihiro Nishi, Kayo Nishi, Yasuichi Ohmoto
}

\begin{abstract}
Interleukin 1 (IL-1) possesses as an intercellular signal a wide spectrum of inflammatory, metabolic, haematopoetic, immunological, and reparative properties and can be a mediator not only of host defence but also of disease. Reduction of IL-1 can decrease the inflammatory host response. A human recombinant IL-1 receptor antagonist (IL-1ra) was used to block IL-1 after intraocular lens implantation in rabbits. Seventeen rabbits underwent intercapsular phacoemulsification and posterior chamber lens implantation. A $100 \mu \mathrm{g}$ dose $(0.1 \mathrm{ml})$ of IL-1ra $(1 \mathrm{mg} / \mathrm{ml})$ was injected into the anterior chamber at the end of surgery in seven rabbits. The 10 rabbits serving as the controls received no IL-1ra. Postoperatively, all rabbits were observed with a slit-lamp, and the aqueous flare intensity was measured with a laser flare cell meter at 12 hours, 1, 2, 3, and 4 days and thereafter at 1, 2, 3, and 4 weeks. Aqueous flare intensity was significantly lower on days 2 and 3 , and fibrin deposition much less marked in the eyes treated with IL-1ra, compared with the controls. The results suggest that IL-1 is involved in the postoperative inflammation that occurs after intraocular lens implantation and the use of the IL-1ra would be valuable for reducing this problem.

(Br F Ophthalmol 1994; 78: 917-920)
\end{abstract}

The cytokine interleukin 1 (IL-1) functions as an intercellular signal and regulates locally and, at times, systemically the immunological, inflammatory, and reparative host response to injury. ${ }^{1}$ The current studies with recombinant IL-1 in human subjects revealed that IL-1 can be a mediator not only of host defence but also of disease. Its over or prolonged production in either situation, however, will diminish or even impair the normal host functions. Therefore, control of IL-1 synthesis or its effects becomes a target of therapy in many diseases. ${ }^{2}$

In the ophthalmic field, the intravitreal injection of IL-1 is known to cause an acute anterior uveitis in rabbits..$^{3-5}$ Interleukin 1 is synthesised by various ocular cells such as retinal pigment epithelial cells, ${ }^{6}$ corneal cells, ${ }^{7}$ Müller cells, ${ }^{8}$ and lens epithelial cells of human cataracts. ${ }^{9}$ Interleukin 1 was detected in the subretinal fluid of retinal detachment in humans,${ }^{10}$ in the vitreous of patients with proliferative diabetic retinopathy, ${ }^{11}$ and in the aqueous humour following intraocular lens implantation in rabbits. ${ }^{12}$

Interleukin 1 receptor antagonist (IL-1ra) has recently been identified as the first described naturally occurring, endogenous receptor antagonist of any cytokine. It has a molecular weight of 17000-25000 and inhibits IL-1 activities by competitive binding to a specific receptor. ${ }^{13}$ It is produced by monocytes, macrophages, neutrophils, fibroblasts, keratinocytes, and other epithelial cells. ${ }^{14}$ It has been shown in various animal models of disease $e^{1516}$ as well as in humans $^{17-19}$ to block the activity of IL-1. It effectively reduced the inflammatory response of anterior uveitis caused by intravitreal injection of IL-1. ${ }^{20}$ IL-1ra may be effective for reducing postoperative inflammation after intraocular lens implantation.

We performed an experiment in rabbits to examine whether IL-1ra is effective in reducing postoperative inflammation after cataract surgery.

\section{Materials and methods}

\section{SURGICAL PROCEDURE}

Seventeen rabbits weighing 1.5 to $2 \mathrm{~kg}$ were anaesthetised by the ketamine hydrochloride $(5 \mathrm{mg} / \mathrm{kg})$ and xylazine hydrochloride $(2 \mathrm{mg} / \mathrm{kg})$. Before surgery the pupil of the rabbit used was dilated with $1 \cdot 0 \%$ tropicamide and $2 \cdot 5 \%$ phenylephrine. Surgery was performed on one eye only. Intercapsular phacoemulsification following a small upper linear anterior capsulotomy was performed. To each $500 \mathrm{ml}$ of balanced salt solution (Alcon Inc, Fort Worth, Texas, USA), 1 ml of adrenaline hydrochloride at a concentration of $1 \mathrm{mg} / \mathrm{ml}$ and 1000 units of sodium heparin were added to facilitate pupillary dilatation and reduce the fibrinous reaction during surgery. After a posterior chamber lens with modified C loop and $6.5 \mathrm{~mm}$ optic was implanted, the axial anterior capsule was removed in such a manner so that the remaining anterior capsule covered the intraocular lens margin.

A $0 \cdot 1 \mathrm{ml}$ aliquot $(100 \mu \mathrm{g})$ of human recombinant IL-lra, (Ohtsuka Pharmaceutical, Tokushima, Japan, $1 \mathrm{mg} / \mathrm{ml}$ ) was injected into the anterior chamber at the end of surgery in seven rabbits, and $0.1 \mathrm{ml}$ of BSS was injected 
into 10 rabbits serving as the controls. A 30 gauge disposable needle attached to a $1 \mathrm{ml}$ syringe was pushed from the limbus across the corneal stroma to make a long channel to prevent leakage of the aqueous humour after withdrawal of the needle. An antibiotic ointment and $1 \%$ atropine sulphate ointment were then instilled.

\section{POSTOPERATIVE LASER FLARE CELL METRY AND} SLIT-LAMP EXAMINATION

The anterior segment was carefully observed with a hand held slit-lamp (SL-14, Kowa Co, Japan), and aqueous flare was measured with a laser flare cell meter (FC-1000, Kowa Co) at 12 hours, 1, 2, 3, and 4 days, and thereafter 1, 2, 3, and 4 weeks. At each measurement, one of three masked observers measured the flare intensity of each eye five to 10 times. After the higher or lower readings were omitted, the median value among at least five remaining readings was determined, and the values from seven treated or 10 untreated eyes were then average for each group. The mean value obtained was expressed as mean flare intensity for each group at each measurement in photon counts/millisecond. The regression equation between photon count and protein concentration (albumin) determined by the manufacturer is $\mathrm{Y}=-1.55+1.07 \mathrm{X} ; \mathrm{Y}=\log$ $\mathrm{y}$, and $\mathrm{X}=\log \mathrm{x} ; \mathrm{y}$ is protein concentration in $\mathrm{mg} / \mathrm{ml}$, and $x$ is photon count $/ \mathrm{ms}$. Coefficient of correlation $r=0.95$. Accordingly, a reading of 457 photons $/ \mathrm{ms}$ equals $20 \mathrm{mg}$ albumin $/ \mathrm{ml}$.

Six months after surgery, all rabbits underwent slit-lamp examination again to observe secondary cataract formation.

\section{Results}

\section{LASER FLARE CELL METRY}

In the untreated eyes, the mean aqueous flare was at its highest on day 2. At the same time, the remaining anterior capsule came in contact with the posterior chamber lens, and the lens epithelial cells (LECs) under the capsule began to proliferate and opacify. The aqueous flare decreased gradually thereafter, while the anterior capsule opacification caused by LEC prolifera-

Figure I Aqueous flare lens implantation in rabbit eyes. $\star^{\star}$ and $\star \star$ indicate statistically significant differences at $p<0.05$ and $p<0 \cdot 01$, respectively.

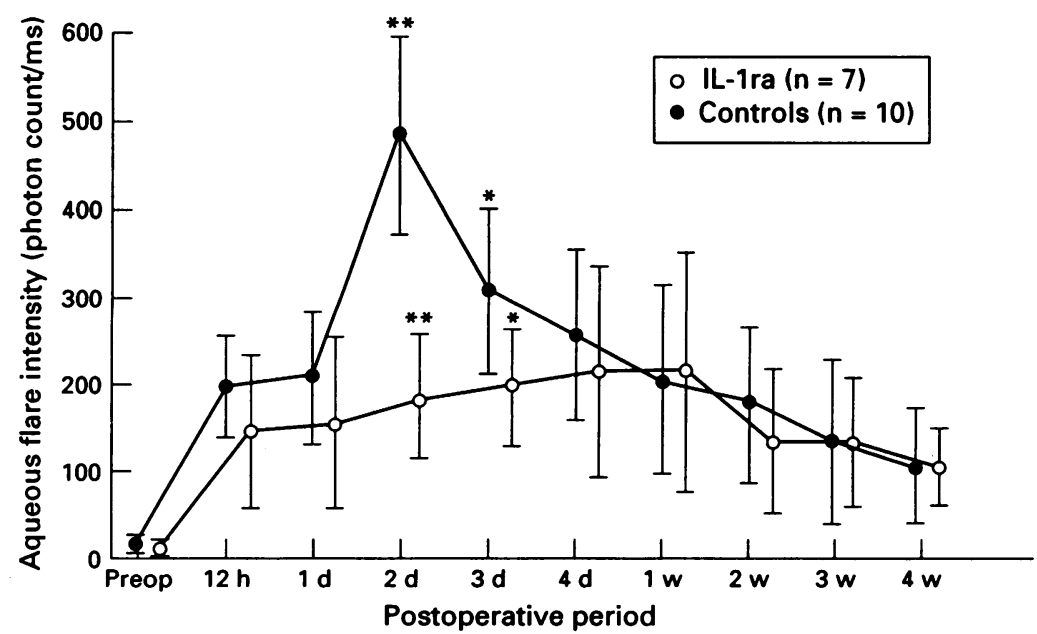

tion increased. Compared with the controls, in the eyes treated with IL-1ra, the mean value of the aqueous flare intensity was lower at every measurement, with the exception of the value at week 1 . The mean value rather increased towards the end of week 1 and then decreased in the eyes treated with the IL-1ra injection. The difference in the mean value of the aqueous flare intensity between both groups was statistically significant on day $2(p<0.01)$ and day $3(p<0.05)$ (multiple comparisons according to Scheffe's method) (Fig 1).

\section{SLIT-LAMP EXAMINATION}

Fibrin deposition was seen in every control eye on days $1-4$, and it needed 2 to 4 weeks to disappear. In contrast with the untreated eyes, fibrin deposition was much less marked and appeared later in the treated eyes, as determined by the slit-lamp examination.

All control eyes showed obvious secondary cataract formation with capsular opacification and synechiae on slit-lamp examination 6 months after surgery. Red reflex from the fundus could hardly be detected. Two of seven treated eyes showed obviously less secondary cataract formation and less capsular opacification, so that the red reflex was evident. We submitted these two eyes and one control eye chosen randomly, to histopathological examination to observe specifically the capsular bag in those eyes.

\section{HISTOPATHOLOGICAL EXAMINATION}

In the capsular bag of the two treated eyes, LEC proliferation was generally much less marked than that in the control eye. In the former, a few lens epithelial cells were observed on the posterior capsule, whereas lens epithelial cells were thickly layered in the latter.

\section{Discussion}

Though our results are based only on one experiment, they showed that human IL-1 ra decreased postoperative inflammation after intraocular lens implantation in the rabbit eye when it was injected into the anterior chamber at the end of surgery. Its significant (decreasing) effect on aqueous flare intensity was manifested after 2 to 3 days. The gradual increase in flare intensity thereafter suggests that IL-1 ra disappeared gradually. IL-1ra may have been metabolised or cleared in those eyes.

Yokoyama $^{12}$ reported that the IL-1 B concentration in the anterior chamber at day 7 after intraocular lens implantation in rabbits was $10 \cdot 12$ (SD 3.96) ng/ml aqueous humour; Rosenbaum et $a l^{20}$ injected $75 \mu \mathrm{g}$ of human recombinant IL-1 ra intravitreally in rabbit eyes to assess the potential activity of the IL-1ra in ocular inflammation induced by the intravitreal injection of IL-1. In the present study, we chose the dose of IL-1ra, because it appeared sufficient to block IL-1 in the anterior chamber of the rabbit and, therefore, to assess the effect.

Even though the IL-1ra used was the human antagonist, it effectively blocked IL-1 in the rabbit eye. There are parallel results ${ }^{20}$ that 
human IL-1ra reduced rabbit ocular inflammation induced by exogenous human IL-1. Interleukin 1 is known to induce IL-1 synthesis during proliferation of cell production. ${ }^{621}$ These facts suggest that human IL-1ra can bind competitively to the rabbit IL-1 receptor. Although the aqueous flare intensity reached almost the same level as that of the control animals, the significant effect at days 2 and 3 seemed to result in less marked fibrin deposition in the eyes receiving the IL-1ra injection. Sustained release of IL-1ra using a proper drug delivery system might work more effectively to reduce disruption of the blood-aqueous barrier.

From the histopathological examination, we were uncertain whether the less marked secondary cataract in two of seven eyes was actually caused by the effect of IL-1ra injection. IL-1 is known to increase epithelial cell division in general. ${ }^{\prime}$ It increased the tritiated thymidine incorporation into cultured lens epithelial cells of human cataracts in our vitro study. (Symposium on Cataracts and Refractive Surgery, 11 April, 1994, Boston) Because only one eye in each rabbit was treated surgically in this study, this might be due to differences in proliferation of lens epithelial cells in the individual rabbit. Moreover, not all eyes underwent histopathological examination. Further study is needed to confirm whether IL-1 ra has a suppressive effect on lens epithelial cell proliferation.

Our results suggest that IL-1 is implicated in the postoperative inflammation after intraocular lens implantation, as it was detected in the aqueous humour following intraocular lens implantation in rabbits. ${ }^{12}$ Interleukin $6^{22}$ was detected in the aqueous humour following intraocular lens implantation in humans. Interleukin 6 caused an acute inflammation subsequent to the intravitreal injection ${ }^{22}$ and is known to be induced by $\mathrm{IL}-1^{2324}$ in the inflammatory or reparative host response to injury. However, Lundgren et al could not detect IL- ${ }^{25}$ in the aqueous humour after intraocular lens implantation in rabbits; according to the authors this might be because of insufficient assay sensitivity. Cytokines act at concentrations of $10^{-10}$ to $10^{-15}$ $\mathrm{mol} / \mathrm{l}$ to stimulate target cell functions, and such a low concentration range aggravates the detection problems.

During several acute or chronic diseases, the effect of specific blocking of IL-1 has not yet been completely clarified. Rosenbaum and coworkers $^{20}$ reported that IL-1ra was effective in reducing IL-1 induced inflammation in rabbit eyes, but did not produce a significant reduction in inflammation subsequent to an active Arthus reaction or the intravitreal application of endotoxin. A parallel result ${ }^{19}$ was reported that intraventricular injection of IL-1ra attenuated the febrile response to a subsequent intracerebroventricular bolus of IL-1, but had no effect on the response to the endotoxin. Prostaglandin $E_{2}$ $\left(\mathrm{PGE}_{2}\right)$ plays a major role in postoperative inflammation after intraocular lens (IOL) implantation. ${ }^{26}{ }^{27}$ The effect of IL-1ra in the present study may be accounted for by the blockage of IL-1 that stimulates $\mathrm{PGE}_{2}$ synthesis by activating the arachidonic acid cascade. ${ }^{28-30}$ Recent reports ${ }^{31-33}$ showed that IL-1ra inhibits the production and effects of $\mathrm{PGE}_{2}$. This can be supported by the fact that inhibitors of eicosanoid synthesis inhibited the ocular inflammatory effects of exogenous IL-1 $\alpha .{ }^{5}$ However, Kulkarni and Mancino $0^{34}$ have reported that ocular inflammation, induced by surgical paracentesis or intravitreal endotoxin injection, was not associated with $\mathrm{PGE}_{2}$ accumulation in the aqueous humour, so that the eicosanoid inhibitors are not effective for reducing inflammation, and the presence of IL-1like activity could not be detected. Our results and these reports suggest that, with respect to the pathogenetic process involved, surgically induced inflammation with proliferating residual LECs shares a common aspect with inflammation induced by exogenous interleukins but not with that induced by surgical paracentesis or exogenous endotoxin in an eye with an uninjured crystalline lens. Proliferating residual LECs may play an important role here. Residual LECs can disrupt the blood-aqueous barrier after intraocular lens implantation, ${ }^{35}$ which suggests a parallel with the fact that human cataract LECs synthesise IL-1 and PGE ${ }_{2}{ }^{9}$ Thus, in the present study, the IL-1 and $\mathrm{PGE}_{2}$ synthesis by residual LECs, apart from IL-1 production by other cells as a result of surgical trauma, may have been blocked or decreased by IL-1ra, which contributed to the decrease in disruption of the bloodaqueous barrier.

In conclusion, the present study suggests that IL-1 is involved in postoperative inflammation after intraocular lens implantation, and IL-1ra seems to be valuable for decreasing surgically induced inflammation in the rabbit eye. Determining of the role of cytokines in ocular inflammation may lead to new treatments for the control of the effects of these important mediators.

The authors have no proprietary interest in the methods or products mentioned in this paper.

Part of this paper was presented at the symposium on cataract and refractive surgery, 11 May 1993 in Seattle, USA.

1 Di Giovine FS, Duff GW. Interleukin 1: the first interleukin Immunol Today 1990; 11: 13-20.

2 Dinarello CA. Interleukin-1 and interleukin-1 antagonism. Blood 1991; 77: 1627-52.

3 Rosenbaum JT, Samples JR, Hefeneider SH, Howes EL Jr. Ocular inflammatory effects of intravitreal interleukin-1. Arch Ophthalmol 1987; 105: 1117-20.

4 Bhattacherjee $P$, Henderson $B$. Inflammatory responses to intraocularly injected interleukin-1. Curr Eye Res 1987; 6: 929-34

5 Tilden ME, Boney RS, Goldenberg MM, Rosenbaum JT. The effects of topical $\mathrm{S}(+)$-ibuprofen on interleukin-1-induced ocular inflammation in a rabbit model. F Ocul Pharmaco 1990; 6: 131-5.

6 Planck SR, Huang XN, Ansel JC, Robertson JE, Rosenbaum JT. Retinal pigment epithelial cells produce interleukin-1 beta and granulocyte-macrophage colony-stimulating factor in response to interleukin-1 alpha. Curr Eye Res 1993; 12: in respos. 2 .

7 Shams NBK, Reddy CV, Watanabe K, Elgebaly SA, Hanninen LA, Kenyon KR. Increased interleukin-1 activity in the injured vitamin A-deficient cornea. Cornea 1994; 13 156-66.

8 Roberge FG, Caspi RR, Nussenblatt RB. Glial retinal Muller cells produce IL-1 activity and have a dual effect on autoimmune $T$ helper lymphocytes. F Immunol 1988; 140: 2193-226

9 Nishi O, Nishi K, Imanishi M. Synthesis of interleukin-l and prostaglandin $\mathrm{E}_{2}$ by lens epithelial cells of human cataracts BrF Ophthalmol 1992; 76: 338-41.

10 Davis JL, Jalkh AE, Roberge F, Caspi R, Flynn HW Jr Schepens CL, et al. Subretinal fluid from human retina detachment contains interleukin-1. Invest Ophthalmol Vis Sci 1988 (Suppl); 29: 396.

11 Abu el Asrar AM, Maimone D, Morse PH, Gregory S, Reder AT. Cytokines in the vitreous of patients with proliferative 12 Yiabetic retinopathy. Am f Ophthalmol 1992; 114: 731-6. and pseudophakic eyes of rabbits. Acta Soc Ophthalmol fpn 1992; 96: 67-73. 
13 Hannum CH, Wilcox CJ, Arend WP, Fennecke G, Joslin DT, Dripps PL, et al. Interleukin-1 receptor antagonist activity $336-40$.

14 Arend WP. Interleukin-1 receptor antagonist. Adv Immunol 1993; 54: 167-227.

15 Ohlsson K, Bjork P, Bergenfeldt M, Hageman R, Thompson RC. Interleukin-1 receptor antagonist reduces mortality from endotoxin shock. Nature $1990 ; 348: 550-5$.

16 Nast CC, Thompson RC, Dinarello CA. In vivo antiinflammatory properties of recombinant interleukin-1 receptor antagonist (IL-1ra). Lymph Res 1990; 9: 307-400.

17 Rambaldi A, Torcia M, Bettoni S, Barbui T, Vannier E, Dinarello CA, et al. Modulation of cell proliferation and cytokine production in acute myeloblastic leukemia by interleukin-l receptor antagonist and lack of its expression by leukemic cells. Blood 1990; 76: 114-8.

18 Guise TA, Garrett IR, Bonewold LE, Mundy GR. Interleukin-1 receptor antagonist inhibits the hypercalcemia
mediated by interleukin-1. F Bone Miner Res 1993; 8: media

19 Coceani F, Lees J, Redford J, Bishai I. Interleukin-1 receptor antagonist: effectiveness against interleukin-1 fever. Can $\mathcal{F}$ Physiol Pharmacol 1992; 70: 1590-6.

20 Rosenbaum JT, Boney RS. Activity of an interleukin 1 receptor antagonist in rabbit models of uveitis. Arch Ophthalmol 1992; 110: 547-9.

21 Dinarello CA, Ikejima T, Warner STC. Interleukin 1 induces interleukin 1 . Induction of circulating interleukin 1 in rabbits in vivo and in human mononuclear cells in vitro. Immunol 1987; 139: 1902-10.

22 Malecaze F, Chollet P, Cavrois E, Vita N, Arrie JL, Ferrara P. Role of interleukin 6 in the inflammatory response after Role of interleukin 6 in the inflammatory response after cataract surgery. An experime

23 May LT, Torua C, Cozzolino F. Interleukin 6 gene expression in human endothelial cells: RNA start sites, multiple IL-6 proteins and inhibition of proliferation. Biochem Biophys Res Commun 1989; 159: 991-8.

24 Planck SR, Dang TT, Graves D, Tara D, Ansel JC, Rosenbaum JT. Retinal pigment epjthelial cells secrete interleukin-6 in response to interleukin-1. Invest Ophthalmol Vis Sci 1992; 33: 78-82.
25 Lundgren B, Ocklind A, Holst AH, Harfstrand A. Inflammatory response in the rabbit eye after intraocular implantatio with poly(methyl methacrylate) and heparin surface modified intraocular lenses. F Cataract Refract Surg 1992; 18: 65-70.

26 Miyake K, Mibu H, Horiguchi M, Shirasawa E. Inflammatory mediators in postoperative aphakic and pseudophakic babon es Arch Ophthalmol 1990; 108: 1764-7.

27 Törngren L, Roltsen W, Lundgren B. PGE, and lencocytes level in aqueous humor after lens extraction and intraocular level in aqueous humor after lens extraction and intraocular 1993; 1: 151-7.

28 Chang J, Gilman SC, Lewis AJ. Interleukin-1 activates phospholipase $\mathrm{A}$ in rabbit chondrocytes: a possible signal for IL-1 action. F Immunol 1986; 136: 1283-7.

29 O'Neill LAJ, Barett ML, Lewis GP, Induction of cyclooxyenase by interleukin-1 in rheumatoid synovial cells. oxygenase by interleukin-1
FEBS Lett 1987; 212: 35-9.

30 Farrar WL, Humes JL. The role of arachidonic acid metabolism in the activities of interleukin 1 and $2 . \mathcal{F}$ Immunol 1985; 135: 1153-9.

31 Meyers KP, Czachowski CL, Coffey JW. Effect of treatment with interleukin-1 receptor antagonist on the development of carrageenan-induced pleurisy in the rat. Inflammation 1993; 17: $121-34$

32 Conti P, Barbacane RC, Felaco M, Grilli A, Placido FC, Reale $M$. Human recombinant interleukin-1 receptor antagonist M. Human recombinant interleukin-1 receptor antagonist
(hr IL-1 RA) inhibits prostaglandin $E_{2}$ generation but not (hr IL-1 RA) inhibits prostaglandin $\mathrm{E}_{2}$ generation but not alkaline phosphatase activity by in vivo chronicgranulomatous

33 Seckinger $\mathrm{P}$, Klein-Nulend J, Alander C, Thomson RC, Dayer JM, Raisz LG. Natural and recombinant human IL-1 receptor antagonists block the effects of IL-1 on bone resorption and prostaglandin production. F Immunol 1990; 145: 4181-4.

34 Kulkarni PS, Mancino M. Studies on intraocular inflammation produced by intravitreal human interleukins in rabbits. $E x p$ produced by intravitreal

$35 \mathrm{Nishi} \mathrm{O}$, Nishi K. Disruption of the blood-aqueous barrier by residual lens epithelial cells after intraocular lens implantation. Ophthalmic Surg 1992; 23: 325-9. 